\title{
Article
}

\section{Awareness of alternative gluten-free grains for individuals with coealiac disease}

\author{
Laheri, Zainab and Soon, Jan Mei
}

Available at http://clok.uclan.ac.uk/23586/

Laheri, Zainab and Soon, Jan Mei ORCID: 0000-0003-0488-1434 (2018)

Awareness of alternative gluten-free grains for individuals with coealiac disease. British Food Journal, 120 (12). pp. 2793-2803. ISSN 0007-070X

It is advisable to refer to the publisher's version if you intend to cite from the work. http://dx.doi.org/10.1108/BFJ-05-2018-0329

For more information about UCLan's research in this area go to http://www.uclan.ac.uk/researchgroups/ and search for < name of research Group>.

For information about Research generally at UCLan please go to http://www.uclan.ac.uk/research/

All outputs in CLoK are protected by Intellectual Property Rights law, including Copyright law. Copyright, IPR and Moral Rights for the works on this site are retained by the individual authors and/or other copyright owners. Terms and conditions for use of this material are defined in the policies page.

\section{CLoK}

Central Lancashire online Knowledge www.clok.uclan.ac.uk

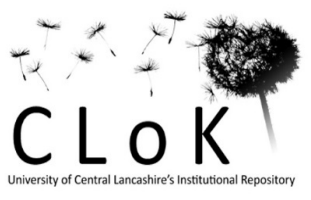




\section{Abstract}

Purpose: Coeliac disease (CD) is a prevalent autoimmune disorder, affecting 1 in 100 of all individuals in the UK. Currently, the only treatment for CD is complete avoidance of gluten, a protein commonly found in wheat, rye and barley. The use of alternative grains (AG) is highly recommended to individuals with CD to improve and diversify their diet. This study aims to determine the current knowledge of the gluten free diet (GFD), consumption rates of $A G$ and awareness of $A G$, for individuals diagnosed with $C D$.

Methodology: A total of 100 participants were recruited via local coeliac support groups as well as an 'Allergy and Free From Show', to participate in a survey. Consent was obtained from all organisations and all individual participants, prior to collecting data. The questionnaire consists of 10 questions, related to participants' demographic characteristics, knowledge of gluten free food (GFF) and AG and consumption rate of AG. Chi-Square $\left(\chi^{2}\right)$ analyses were conducted to compare the variables between gender and time of diagnosis.

Findings: Overall, both genders possessed good knowledge of the GFD. Yogurt, vinegar and oats resulted in the highest incorrect responses. It was found that females possesed better knowledge of both GFF and AG. Rice, quinoa and corn were amongst the most popular AG consumed whilst Job's tears, fonio and sorghum were the least consumed grains. Females reported a higher consumption rate of $A G$ than males. Additionally, those more recently diagnosed had poorer knowledge of the GFD, reduced consumption rates of AG and poor awareness of $A G$.

Originality: It can be suggested that the incorporation of $A G$ into the diet, can prove beneficial for coeliacs and that both knowledge and education, play a fundamental role in determining consumption rates amongst individuals.

Keywords: alternative grains; coeliac disease; diagnosis; gluten free; nutrition

\section{Introduction}

Coeliac disease (CD) has now developed into a prevalent autoimmune disorder, affecting 1 in 100 of all individuals in the UK (Ciacci et al., 2015). The increased incidence of this chronic inflammatory disease is a growing concern, having increased in fourfold over the last two decades (West et al., 2014). Though initially thought to exist exclusively in European 
countries, $C D$ is now regarded as one of the most common genetic diseases, with a $0.9 \%$ prevalence worldwide (Lionetti et al., 2015).

$\mathrm{CD}$ is developed when gluten, a protein matrix formed by gliadin and glutenin commonly found in wheat, rye and barley is consumed by genetically predisposed individuals, causing damage to the lining of their small intestine. Patients diagnosed with CD possess villous atrophy (flattening of the villi) and crypt hyperplasia (elongated crypts between villi), leading to a reduced absorption of essential nutrients and consequently malnutrition (Fei et al., 2012; Green et al., 2015). Following gluten ingestion, individuals with CD will exhibit several short-term and long-term consequences, which differ in both time (certain symptoms will disappear in hours, while others may persist for weeks) and severity (ranging from barely noticeable to extreme discomfort) (Pulido et al., 2013). Common gastrointestinal symptoms associated with this enteropathy include abdominal discomfort, altered bowel habits, severe diarrhoea and heartburn (Castillo et al., 2015). Whilst destruction of the gut is a major component of the illness that is $C D$, the issues unfortunately do not stop there. This systematic disease can also have a detrimental effect on many vital organs, such as the heart, skin, liver and brain (Moreno et al., 2014). Examples of extraintestinal manifestations include anaemia, osteoporosis, liver abnormalities and dermatitis herpetiformis (a skin manifestation of CD) (Leffler et al., 2015). This vast array of inevitable symptoms that are associated with this autoimmune disorder, places a heavy burden on any individual with CD.

Currently, the only proven treatment for $C D$ is avoidance of all gluten containing products. Adherence to this strict diet allows the gut to heal and efficiently absorb nutrients, thus reducing any long-term consequences associated with CD (Jnawali et al., 2016). With 38\% of individuals who removed gluten from their diet, showing an immediate improvement in overall health, the positive influence of the gluten free diet (GFD) is clearly illustrated (Gaillard, 2016). In fact, strictly adhering to the GFD has been shown to decrease long-term health risks, such as gastrointestinal malignancies, osteoporosis and anaemia. Moreover, improvement in overall quality of life and consequently psychological wellbeing is a noticeable benefit, for those adhering to the GFD (Hall et al., 2009). Whilst the positive influence of the GFD is clearly illustrated, it is important to note that there are many cases of refractory CD, which unfortunately do not respond to the GFD. In fact Gaillard (2016), found that only $38 \%$ of individuals who removed gluten from their diet, showed an immediate improvement in overall health, with all other individuals experiencing persistent symptoms of $C D$ and continual villous atrophy. This is further reinforced by Paarlahti et al. 
(2013), who found that $25 \%$ of individuals continued to suffer from the persistent symptoms of CD, despite committing to a strict GFD. Furthermore, complete compliance to the severely stringent regime that is the GFD, requires constant vigilance and therefore can prove to be much harder than originally thought. Gluten features as a prominent protein in countless foods, including pasta, bread, cereals and confectionary. Gluten has unique structural and functional properties and is known to provide visco-elasticity, taste, texture, ability to bind fat and water, consequently proving gluten as an essential component of many foods (Day et al., 2016). Therefore, with gluten dominating the food industry, it is no surprise why complete avoidance of this persistent protein, is challenging (Makharia, 2014). Hidden sources of gluten can prove to present an additional challenge. . For example, sauces and marinades, processed meats, soups and alcohol, though in minimal amounts, may still contain gluten and thus extra care should be taken when consuming these foods (Lebwohl et al., 2015). Whilst it is common knowledge, that those with CD should avoid all wheat based food products, it is also important to remember that gluten is frequently added to many inconspicuous foods It is clear that gluten free food (GFF) are a necessity, in order to accommodate for the millions of people, who are currently eliminating this life threatening protein from their diet.

Alternative grain sources to the GFD (including cereals, minor cereals and pseudocereals), can be categorised under three key grains; cereals (rice, corn and sorghum), minor cereals (fonio, teff, millet and job's tears) and pseudocereals (buckwheat, quinoa and amaranth). All are rich in a variety of nutrients, minerals, phytochemicals and dietary fibre and therefore, their consumption has been widely recommended to all individuals (Li et al., 2016). Furthermore, all AG are lacking in gluten, an essential component for coeliacs, thus providing an additional benefit for those with $\mathrm{CD}$. Whilst whole grains are a means of improving the quality of diet, the consequent improvement in quality of life is perhaps the true benefit for coeliacs. Therefore, the use of these alternative grains (AG) is highly recommended to individuals with CD (Comino et al., 2013). Despite this, coeliacs are known to have a low consumption rate of AG. Despite knowing the many benefits of AG, consumption rates amongst coeliacs and non-coeliacs are low and rapidly declining (Nicklas et al., 2013: Mann et al., 2015). The increased expense of grain products, or the preferred convenience of buying readily prepared foods containing refined grains, as opposed to buying and preparing raw grains, may attribute to this damaging consequence (Nicklas et al., 2013). 
Whilst finance and convenience are both influential factors of current diet status for coeliacs and non-coeliacs, research indicates that lack of knowledge is perhaps the most detrimental influencer. Many individuals with CD possess an ingrained belief that all grains contain gluten and this ignorance and fear of contamination is causing reluctance amongst coeliacs, ultimately leading to reduced whole grain consumption (Kmietowicz, 2017). Furthermore, recent research indicates that elimination of grains from the diet, due to poor education, is associated with a range of health problems, specifically the increased incidence of heart attacks (Lebwohl et al., 2017). A further explanation for the reduced consumption rates of AG amongst coeliacs could be due to the distribution of vouchers, which allow individuals to purchase GFF at a discounted price. This particular strategy is utilised in many countries including the UK, to assist coeliacs in managing their condition. GFF are made available on prescription to patients with $C D$. In fact, $90 \%$ of patients with $C D$ relied on prescriptions for GFF (Robins et al., 2008). However, this may prove to be more disadvantageous and detrimental to overall health, as offering coeliacs GFF at discounted prices, discourages the consumption of AG (Muhammad et al., 2017). This is an issue, as the consumption of AG, provides a clear alternative for coeliacs, which is both proven and tolerable. Thus, this study aims to determine the knowledge of individuals diagnosed with $C D$, on their current knowledge of the GFD, their consumption rates of AG and awareness of AG that could positively influence their health status.

\section{Materials and methods}

Subject recruitment

This particular research targeted both male and female individuals of $\geq 18$ years old, who were diagnosed with $C D$ (Table 1). A total of 100 participants were recuited to take part in this study. Previous study looking into a similar area of research recruited 50 participants and found that the use of AG was more beneficial in improving the nutritional profile of individuals with CD (Lee et al., 2009). This coupled with the time restraints and the participation of an extremely targeted population (individuals diagnosed with $C D$ ), indicates that a minimum of 100 participants is sufficient. Participants were recruited via local coeliac support groups, as well as an 'Allergy and Free From Show'. Whilst attending the show, additional support groups such as Coeliac UK and Allergy Awareness were approached, to recruit further participants. Consent was obtained from all organisations and all individual participants, prior to collecting data. The study was approved by the University ethics committee prior to subject recruitment. 
Questionnaire development

142 The questionnaire was composed of 10 short questions, related to participants' demographic characteristics (7 questions), knowledge of GFF and AG (2 questions with sub-choices) and consumption rate of AG (1 question with sub-choices). Participants were asked to select correct GFF from a checklist. All 15 food items were compared with the Coeliac UK Gluten

146 Free (GF) Checklist (Coeliac UK, 2018), to positively determine which items were GF. To test

147 the awareness of AG participants were asked to identify if it was possible for three different

148 GF grains (amaranth, quinoa and buckwheat), to be used in the production of six generic 149 food items (chocolate cake, vegetable soup, tomato pasta, porridge, blueberry muffins and rice pudding). Description and photos of the grains were included in the survey for participants who may not have heard of the AG. Based on Haros and Sanz-Penella (2017), all three types of grains can be utilised to make the six food items. The questionnaire given to all participants was adapted from others used in similar studies (Simpson et al., 2011; Silvester et al., 2016). A pilot test was also conducted with $10 \mathrm{CD}$ patients, prior to collecting main data, to assess the feasibility, clarity and time taken to complete the questionnaire. After completion of the pilot study, slight modifications were made to the questionnaire. The number of questions was reduced from 14 to 10, in an effort to allow participants to focus purely on their knowledge and awareness of AG.

Statistical analyses

Statistical analyses were conducted using IBM SPSS Statistics Version 23. A Chi-Square $\left(\chi^{2}\right)$ analysis was carried out, to test for a number of different variables.

\section{Results and Discussion}

A total of 100 participants (23 males and 77 females) completed the survey. All participants were diagnosed with $\mathrm{CD}$ (Table 1). The large gender difference within participants is plausible, as $C D$ is more prevalent in women than men, with $60-70 \%$ of individuals diagnosed with CD being women (Shah and Leffler, 2010). The fact that women, on average, are more likely to use healthcare services than men, can also explain this (Pinkhasov et al., 2010). More than $60 \%$ of the participants reported that they adhered to strict GFD while slightly less than $20 \%$ follow GFD most of the time.

Insert Table 1 here

\section{Knowledge of GFF and ingredients}


Statistical analysis highlighted that of the fifteen different food items, there was a significant difference between males and females in five of the food items. These included semolina, vinegar, buckwheat, cocoa and eggs (Table 2). Both genders scored equally (100\%) on three of the fifteen food items (milk, chicken and rye). Males scored 17\% higher on one food item (oats), than females. Females scored higher on all other food items, indicating that overall, females possess an increased knowledge of the GFD. It is important to note, that adequate knowledge of the GFD is the key to successfully managing CD and that, this knowledge is essential for dietary compliance. Without sufficient knowledge, patients are at risk of accidental consumption of gluten and consequently continued villous atrophy (Ciacci et al., 2015). Overall, both genders possessed good knowledge of the GFD. This is justifiable, since most participants had been confirmed with $C D$ through clinical diagnosis, as opposed to self-diagnosis. Hence, it can be assumed that patients would have received some form of information regarding their condition and management. This, coupled with the fact that all individuals were recruited at a place where they were actively seeking out information (i.e. "Allergy and Free From Show" and coeliac support groups), indicates that all participants should possess enough knowledge of GFF.

Furthermore, this study found that females had an increased knowledge of the GFD, than males and is consistent with previous research, which suggests that females have a higher adherence to the GFD, due to their increased knowledge (Leffler et al., 2008). Yoghurt produced the most incorrect responses by both genders. This could be due to misconception by participants and lack of specificity of the question ("Is yoghurt GF?"), as although plain yoghurt is considered to be GF, yoghurt which is flavoured or has added grains cannot be consumed by coeliacs (Coeliac UK, 2018). Oats produced the third most incorrect answers and was the only food item, whereby females scored lower than males. There has been much controversial evidence surrounding the addition of oats in the GFD. Whilst the consumption of pure oats has been deemed safe for consumption, oats contaminated with gluten are harmful (Fric et al., 2011). However, studies have reported that oats may be immunotoxic in patients with CD (Arentz-Hansen et al., 2004; Tuire et al., 2012). Among patients that reacted to oats, the abnormal immunological response against avenins may have been triggered by a similar mechanism to that of gluten (Comino et al., 2015). Other studies revealed that coeliac patients who consumed oats showed no signs of intestinal inflammation (Kaukinen et al., 2013; Lionetti et al., 2018). This demonstrates the 
importance of ensuring the safety of oats (prevention of cross contamination with gluten containing cereals) and the need to identify oat varieties with no toxicity towards patients with CD (Comino et al., 2011). Times of diagnosis may also affect the level of awareness of GFF. Results indicated that there was a significant difference in four of the food items. These included yoghurt $\left(\chi^{2}(3)=\right.$ 26.984, $\mathrm{p}=<0.001)$, vinegar $\left(\chi^{2}(3)=29.779, \mathrm{p}=<0.001\right)$, buckwheat $\left(\chi^{2}(3)=7.827, \mathrm{p}\right.$

$217=<0.05)$ and soy sauce $\left(\chi^{2}(3)=15.283, p<0.05\right)$. In three of these food items (vinegar,

218 buckwheat and soy sauce), it was found that those individuals diagnosed before 2003, had the highest percentage of correct answers. Additionally, for these three food items, those diagnosed in 2017 had the lowest percentage of correct answers. Patients diagnosed at an earlier stage (before 2003) had better knowledge than those diagnosed later. A difference does exist in adherence, between newly diagnosed individuals and those who have observed the GFD long-term and that this difference is due to lack of knowledge exhibited by newly diagnosed individuals (Ludviggson et al., 2014). In this case, it is recommended that at the time of diagnosis, individuals with $\mathrm{CD}$ should be referred to a registered dietitian and encouraged to join coeliac support groups, in order to attain this knowledge and consequently improve their nutritional profile (Ciacci et al., 2015).

\section{Consumption of alternative grains}

230 Participants were asked how often they consume AG on a weekly basis.

Table 3 highlights the \% of grain consumption for both genders on a weekly basis. Job's tears, fonio and sorghum were the least consumed grains. Both amaranth and millet were consumed at a higher rate than the above three grains although their consumption were still relatively low. Quinoa and corn were relatively popular amongst both genders. Rice was the most popular grain, with all males consuming it at some point during the week and only a small population of females, not consuming it at all. Of the 10 grains, there was a significant difference between male and females in only one of the grains - buckwheat $\left(\chi^{2}(2)=9.105\right.$, $p<0.05)$. More than $90 \%$ of males reported never having consumed buckwheat while slightly more than $20 \%$ of females reported consuming buckwheat once per week.

Insert Table 3 here

Time of diagnosis revealed a significant difference in consumption rates of three types of grains. These were quinoa $\left(\chi^{2}(6)=10.467, p<0.001\right)$, teff $\left(\chi^{2}(6)=46.490, p<0.001\right)$ and millet $\left(\chi^{2}(6)=30.262, p<0.001\right)$. This suggests that for these three grains, there was 
a varied consumption rate amongst individuals diagnosed at different times, as opposed to all other grains, whereby consumption rates were similar, regardless of time of diagnosis. For individuals diagnosed in 2017, amaranth, sorghum, fonio and millet were not consumed at all. Individuals diagnosed prior to 2003 to 2016 did not consume job's tears.

Females reported a higher consumption rate than males and those diagnosed earlier were more inclined to consume AG, than those more recently diagnosed. This could simply be because, females and those diagnosed earlier, have an increased awareness of the nutrient deficient GFD and consequently possess better knowledge of the influence of AG (Leffler et al., 2008). Furthermore, the increased consumption rate of AG exhibited by females can also be explained by the fact that females, in general, are more interested in cooking as well as trying new foods and recipes, as opposed to males (FSA, 2014). For all participants, regardless of gender and time of diagnosis, rice was the most frequently consumed grain. Valitutti et al. (2017), who also found increased rice consumption in individuals with CD, supports this.

Overall AG consumption for all participants was quite low. This is consistent with previous research, which indicates that those from the coeliac community have low consumption rates of AG (Nicklas et al., 2013). Misconceptions, such as, believing a grain contains gluten when it is actually GF, could potentially play a role in explaining this low rate of consumption (Kmietowicz, 2017). However, for this particular study, the true reasons for the avoidance of $A G$ is unknown (a limitation), and hence further research into this area could prove beneficial for health care professionals, as a means of educating the coeliac community, thus increasing adequate grain consumption and subsequently improving overall nutritional status (Valitutti et al., 2017).

\section{Awareness of utilisation of AG in different food items}

273 Overall, females had a higher percentage of correct responses for foods made with

274 amaranth and buckwheat. In contrast, males had a higher percentage of correct responses

275 for foods made with quinoa; however the difference was relatively small for most food 276 items, suggesting that females have a higher awareness of AG. Additionally, both males and

277 females had a higher incorrect response rate for blueberry muffins, in comparison to all 278 other food items. Food uses of rice pudding were better known by males and females, with 279 both genders producing a higher percentage of correct responses (Table 4). 
Overall, it can be said that those diagnosed before 2003, have a much higher correct response rate than those diagnosed after this time, suggesting their increased awareness of AG (Table 5). All participants diagnosed in 2003 , scored $78 \%$ or higher. In contrast, those who were more recently diagnosed (2017), had poorer awareness of AG, with all individuals diagnosed in 2017 producing the highest percentage of incorrect responses. Most individuals, regardless of time of diagnosis, were more aware of the food uses of quinoa, with participants having a high correct response rate for this grain.

290

Insert Table 5 here

292

Females had a greater awareness of AG in comparison to males. Additionally, newly diagnosed individuals had poorer awareness when compared to those diagnosed before 2003. This can again be explained by the fact that these individuals already possess an increased knowledge regarding the nutritional limitations of the GFD and as such have become aware of potential pseudocereals that could provide a healthy alternative (Leffler et al., 2008). Also, the increased awareness of AG exhibited by females can again be due to their increased likelihood of both cooking and trying new recipes, in comparison to males (FSA, 2014). Another explanation could be due to the increased commercialisation of these grains (Moreno et al., 2014). The prevalence of CD has greatly increased and hence further scrutiny has been placed on the GFD, steering coeliacs towards viable alternatives (Ciacci et al., 2015). This has warranted food industries to produce and advertise a range of GFF incorporated with these versatile grains. Hence, this global publicity has provided a means of education for coeliacs (Boukid et al., 2017).

\section{Limitations}

308 All participants were recruited via an 'Allergy and Free From Show' and coeliac support 309 groups and thus may already possess a heightened awareness of the GFD and AG, when 310 compared to other coeliacs. Moreover, participants' place of recruitment increases the 311 likelihood of individuals having an interest in the study and being more positively motivated.

312 Therefore, results may not be an accurate representation of the overall coeliac community.

313 Furthermore, all data was collected via self-reported questions.

\section{Conclusion}


There is overwhelming evidence that the GFD is the only proven treatment for CD. However

317 it can be challenging to adhere to and CD patients should ensure they consume a varied

318 GFD to ensure they meet their nutritional requirements. This study found that females

319 possesed better knowledge of both GFF and AG. Additionally, those more recently diagnosed

320 had poorer knowledge of the GFD and AG and reduced consumption rates of AG.

321 Pseudocereals are alternative sources of grains that can be incorporated into the diet.

Whilst incorporation of pseudocereals into the diet can provide an essential alternative for coeliacs, results from this study clearly implicate that grain consumption is far from adequate. It seems that knowledge plays a fundamental role in determining consumption rates of AG. Therefore, the need for sufficient education is not only recommended but is absolute necessary, to improve the current nutritional status, of those suffering from the chronic autoimmune disorder that is CD.

\section{Recommendations for future research}

To further improve the study, research into the current diet status of the participants can be beneficial in establishing if individuals are able to meet their daily nutritional requirements. Dietary status can also be utilised, to influence the incorporation of specific AG into the diet, if individuals are lacking in key nutrients. Additionally, an analysis into the reasons behind avoidance of certain grains, could prove beneficial in increasing consumption rates amongst coeliacs. Long-term follow up studies among adults with CD and the uptake of AG and GF sources rich in nutrients should be carried out. It is also recommended that further studies on the ignorance of AG and GFF be conducted as this can directly affect adherence to GFD.

\section{References}

Arentz-Hansen, H., Fleckenstein, B., Molberg, Ø., Scott, H., Koning, F., Jung, G. et al. (2004), "The molecular basis for oat intolerance in patients with celiac disease", PLoS Medicine, Vol. 1 No. 1 , e1.

Boukid, F., Folloni, S., Sforza, S., Vittadini, E. and Prandi, B. (2017), "Current trends in ancient grains-based foodstuffs: Insights into nutritional aspects and technological applications", Comprehensive Reviews in Food Science and Food Safety, Vol. 17 No. 1, pp. 123-136.

Castillo, N. E., Theethira, T. G. and Leffler, D.A. (2015), "The present and the future in the diagnosis and management of celiac disease", Gastroenterology Report, Vol. 3 No. 1, pp. 311.

Ciacci, C., Ciclitira, P., Hadjivassiliou, M., Kaukinen, K., Ludvigsson, J. F., McGough, N., Sanders, D. S. Woodward, J., Leonard, J. N. and Swift, G. L. (2015), "The gluten-free diet and its current application in coeliac disease and dermatitis herpetiformis", United European Gastroenterology Journal, Vol. 3 No. 2, pp. 121-135. 
Coeliac UK (2018), "Law on gluten free", available at: https://www.coeliac.org.uk/gluten-freediet-and-lifestyle/food-shopping/law-on-gluten-free/ Accessed 14th Feb 2018.

Coeliac UK (2018), “The gluten free diet”, available at: https://www.coeliac.org.uk/glutenfree-diet-and-lifestyle/gf-diet/. Accessed 3rd April 2018.

Comino, I., Moreno, M. D. L., Real, A., Rodrigues-Herrera. A., Barro, F. and Sousa, C. (2013), "The Gluten-free diet: Testing alternative cereals tolerated by coeliac patients", Nutrients, Vol. 5 No. 10 , pp. $4250-4268$.

Comino, I., Real, A., de Lorenzo, L., Cornell, H., Lopez-Casado, M. A., Barro, F., Lorite, P., Torres, M. I., Cebolla, A. and Sousa, C. (2011), "Diversity in oat potential immunogenecity: basis for the selection of oat varieties with no toxicity in coeliac disease", Gut, Vol. 60, pp. 915922.

Comino, I., de Lourdes Moreno, M., Sousa, C. (2015), "Role of oats in celiac disease", World Journal of Gastroenterology, 21 No. 41, pp. 11825-11831.

Day, I., Augustin, M. A., Batey, I. L. and Wrigley, C. W. (2006), "Wheat-gluten uses and industry needs", Trends in Food Science \& Technology, Vol. 17 No. 2, pp. 82-90.

Fei, B., Green, P. H. R. and Bhagat, G. (2012), "An update on celiac disease histopathology and the road ahead", Archives of Pathology and Laboratory Medicine, Vol. 136 No. 7, pp. 735745 .

Fric, P., Gabrovska, D. and Nivoral, J. (2011), "Celiac disease, gluten-free diet, and oats", Nutrition Reviews, Vol. 69 No. 2, pp. 107-115.

FSA, Foods Standards Agency (2014), "The Food and You Survey", available from: https://www.food.gov.uk/sites/default/files/media/document/food-and-you-2014-uk-bulletin1.pdf. [Accessed 1 Jul 2018]

Gaillard, L. A. (2016), "Navigating gluten-related health disorders and nutritional considerations of gluten-free diets", North Carolina Medical Journal, Vol. 77 No. 3, pp. 180182.

Green P. H. R., Leung, D. Y. M. and Ledford, D. K. (2015), "Celiac disease", Clinical Reviews in Allergy and Immunology, Vol. 135 No. 5, pp. 1099-1106.

Hall, N. J., Rubin, G. and Charnock, A. (2009), "Systematic review: adherence to a gluten-free diet in adult patients with coeliac disease", Alimentary Pharmacology and Therapeutics, Vol. 30 No. 4, pp. 315-330.

Haros, C. M. and Sanz-Penella, J. M. (2017), "Chapter 8: Food Uses of Pseudocereals," in, C. M. Haros and R. Schonlechner, (eds.). Pseudocereals: Chemistry and Technology. USA: John Wiley and Sons, pp. 163-192.

Jnawali, P., Kumar, V. and Tanwar, B. (2016), "Celiac disease: Overview and considerations for development of gluten-free foods", Food Science and Human Wellness Vol. 5 No. 4, pp. 169-176.

Kaukinen, K., Collin, P., Huhtala, H. and Maki, M. (2013), "Long-term consumption of oats in adult celiac disease patients", Nutrients, Vol. 5 No. 11, pp. 4380-4389. 
Kmietowicz, Z. (2017), "Gluten-free diet is not recommended for people without celiac disease", British Medical Journal, Vol. 357, doi: 10.1136/bmj.j2135

Lebwohl, B., Ludvigsson, J. F. and Green, P. H. R. (2015), "Celiac disease and non-celiac gluten sensitivity”, British Medical Journal, Vol. 351 No. 4347, pp. 1-13.

Lebwohl, B., Sao, Y., Zong, G., Hu, F. B., Green, P. H. R., Neugut, A.I ., Rimm, E. B., Sampson, L., Dougherty, L. W., Giovannucci, E., Willett, W. C., Sun, Q.I. and Chan, A. T. (2017), "Long term gluten consumption in adults without celiac disease and risk of coronary heart disease: prospective cohort study", British Medical Journal, Vol. 357 No. 1892, pp. 1-10.

Lee, A. R., Ng, D. L., Dave, E., Ciaccio, E. J. and Green, P. H. R. (2009), "The effect of substituting alternative grains in the diet on the nutritional profile of the gluten-free diet. Journal of Human Nutrition and Dietetics, Vol. 22 No. 4, pp. 359-363.

Leffler, D. A., Edwards-George, J., Dennis, M., Schuppan, D., Cook, F., Franko, D. L., BlomHoffman, J. and Kelly, C. P. (2008), "Factors that influence adherence to a gluten-free diet in adults with celiac disease", Digestive Diseases and Sciences, Vol. 53 No. 6, pp. 1573-1581.

Leffler, D. A., Green, P. and Fasano, A. (2015), "Extraintestinal manifestations of coeliac disease", Nature Reviews: Gastroenterology and Hepatology, Vol. 12 , pp. 561-571.

Li, B., Zhang, G., Tan, M., Zhao, L., Jin, L., Tang, X., Jiang, G. and Zhong, K. (2016), "Consumption of whole grains in relation to mortality from all causes, cardiovascular disease, and diabetes", Journal of Medicine - Baltimore, Vol. 95 No. 33, pp. 1-9.

Lionetti, E., Gatti, S., Galeazzi, T., Caporelli, N., Francavilla, R., Cucchiara, S. et al. (2018), "Safety of oats in children with celiac disease: A double-blind, randomized, placebo-controlled trial", Journal of Pediatrics, Vol. 194, pp. 116-122.e2.

Lionetti, E., Gatti, S., Pulvirenti, A. and Catassi, C. (2015), "Coeliac disease from a global perspective. Best Practice and Research Clinical Gastroenterology”, Vol. 29 No. 3, pp. 365379.

Ludviggson, J. F., Bai, J. C., Biagi, F., Card, T. R., Ciacci, C., Ciclitira, C., Green, P. H. R., Hadjivassiliou, M., Holdoway, A., van Heel, D.A., Kaukinen, K. A. (2014), "Diagnosis and management of adult coeliac disease: guidelines from the British Society of Gastroenterology", Gut, Vol. 63 No. 8, pp. 1210-1228.

Mann, K. D., Pearce, M. S., McKevith, B., Thielecke, F. and Seal, C. J. (2015), "Low whole grain intake in the UK: results from the National Diet and Nutrition Survey rolling programme 2008-11", British Journal of Nutrition, Vol. 113 No. 10, pp. 1643-1651.

Makharia, G. K. (2014), "Current and emerging therapy for celiac disease", Frontiers in Medicine, Vol. 1 No. 6, pp. 1-11.

Moreno, A. M. D. L., Comino, M. and Sousa, M. C. (2014), "Alternative grains as potential raw material for gluten-free food development in the diet of celiac and gluten-sensitive patients", Austin Journal of Nutrition and Metabolism, Vol. 2 No. 3, pp. 1-9.

Muhammad, H., Reeves, S., Ishaq, S., Mayberry, J. and Jeanes, Y.M. (2017), "Adherence to a gluten free diet is associated with receiving gluten free foods on prescription and understanding food labelling", Journal of Human Nutrition, Vol. 9 No. 7, pp. 705-713. 
Nicklas, T. A., Jahns, L., Bogle, M. L., Chester, D.N., Giovanni, M., Klurfeld, D. M., Laugero, K., Liu, Y., Lopez, S., Tucker, K. L. (2013), "Barriers and facilitators for consumer adherence to the dietary guidelines for Americans: the HEALTH study", Journal of the Academy of Paarlahti, P., Kurppa, K., Ukkola, A., Collin, P., Huhtala, H., Maki, M. and Kaukinen, K. disease patients: a large cross-sectional study", BMC Gastroenterology, Vol. 13 No. 75, pp. 1-7.

Pinkhasov, R. M., Wong, J., Kashanian, J., Lee, M., Samadi, D.B., Pinkhasov, M. M. and Shabsigh, R. (2010), "Are men short-changed on health? Perspective on health care utilization and health risk behaviour in men and women in the United States", International Journal of Clinical Practice, Vol. 64 No. 4, pp. 475-487.

Pulido, O., Zarkadas, M., Dubois, S., Maclsaac, K., Cantin, I., La Vieille, S., Godefroy, S. and Rashid, M. (2013), "Clinical features and symptom recovery on a gluten-free diet in Canadian adults with celiac disease", Canadian Journal of Gastroenterology and Hepatology, Vol. 27 No. 8, pp. 449-453.

Robins, G., Akobeng, A., McGough, N., Merrikin, E. and Kirk, E. (2008), "A systematic literature review on the nutritional adequacy of a typical gluten-free diet with particular reference to iron, calcium, folate and B vitamins", available at:

https://www.food.gov.uk/sites/default/files/research-report-gluten-free.pdf [Accessed 6 July 2018].

Shah, S. and Leffler, D. (2010), "Celiac disease: an underappreciated issue in women's health", Women's Health, Vol. 6 No.5, pp. 753-766.

Silvester, J. A., Weiten, D., Graff, L. A., Walker, J. R. and Duerksen, D. R. (2016), "Is it glutenfree? Relationship between self-reported gluten-free diet adherence and knowledge of gluten content of foods", Nutrition, Vol. 7 No. 32, pp. 777-783.

Simpson, S., Lebwohl, B., Lewis, S. K., Tennyson, C. A., Sanders, D. S. and Green, P. H. (2011), "Awareness of gluten-related disorders: A survey of the general public, chefs and patients", European e-Journal of Clinical Nutrition and Metabolism, Vol. 6 No. 5, pp. e227e231.

Tuire, I., Marja-Leena, L., Teea, S., Katri, H., Jukka, P., Paivi, S. et al. (2012), "Persistent duodenal intraepithelial lymphocytosis despite a long-term strict gluten-free diet in celiac disease", American Journal of Gastroenterology, Vol. 107 No. 10, pp. 1563.

Valitutti, F., Lorfida, D., Anania, C., Trovato, C. M., Montuori, M., Cucchiara, S. and Catassi, C. (2017), "Cereal consumption among subjects with celiac disease: A snapshot for nutritional considerations”, Nutrients, Vol. 9 No. 4, pp. 396-405.

Welstead, L. (2015), "The gluten-free diet in the 3rd millennium: rules, risks and opportunities", Diseases, Vol. 3 No. 3, pp. 136-149.

West, J., Fleming, K. M., Tata, L. J., Card, T. R. and Crooks, C. J. (2014), "Incidence and Prevalence of Celiac Disease and Dermatitis Herpetiformis in the UK over two decades: population-based study", The American Journal of Gastroenterology, Vol. 109 No. 5, pp. 757768.

Table 1 Demographic characteristics of participants $(n=100)$ 


\begin{tabular}{ll}
\hline Characteristics & \% \\
\hline Gender & 23 \\
Male & 77 \\
Female & \\
Age & 29 \\
18 to 24 & 16 \\
25 to 34 & 8 \\
35 to 44 & 10 \\
45 to 54 & 19 \\
55 to 64 & 18 \\
65 to 74 & \\
When were you diagnosed with coeliac disease? & 28 \\
2017 & 20 \\
$2010-2016$ & 11 \\
$2003-2009$ & 41 \\
$<2003$ & \\
How have you been diagnosed with coeliac disease? & 59 \\
Duodenal biopsy & 26 \\
Bloodwork & 13 \\
Gene testing & 2 \\
Self-diagnosis & \\
Please describe your current diet. & \\
Unrestricted diet & 1 \\
Gluten free diet occasionally & \\
Gluten free diet most of the time & 10 \\
Strict gluten free diet & 18 \\
Trying to follow a strict gluten free diet, but not always sure & 61 \\
How long have you restricted the amount of gluten in your diet? & 10 \\
Less than or equal to 5 years & \\
Between $6-10$ years & \\
$11-15$ years & 12 \\
$16-20$ years & 19 \\
More than 20 years & \\
Do you avoid or restrict any other foods? & \\
Yes & \\
No & \\
\hline
\end{tabular}

522 Table 2 Knowledge of GFF and ingredients ( $n=100$ and represents number of participants 523 who answered correctly)

\begin{tabular}{lllll}
\hline Food Items & Is it gluten free ? $^{\mathbf{a}}$ & $\begin{array}{l}\text { Males } \\
\mathbf{n}(\%)\end{array}$ & $\begin{array}{l}\text { Females } \\
\mathbf{n}(\%)\end{array}$ & $\chi^{\mathbf{2}}$ \\
\hline Oats & $\checkmark$ & $21(91.3)$ & $57(74.0)$ & 3.1 \\
Milk & $\checkmark$ & $23(100)$ & $77(100)$ & $\mathrm{NC}$ \\
Chicken & $\checkmark$ & $23(100)$ & $77(100)$ & $\mathrm{NC}$ \\
Semolina & $\mathrm{X}$ & $19(82.6)$ & $75(97.4)$ & $6.87 *$ \\
Potatoes & $\checkmark$ & $21(91.3)$ & $77(100)$ & 6.83
\end{tabular}




\begin{tabular}{lllll} 
Yoghurt & $\checkmark$ & $8(34.8)$ & $29(37.7)$ & 0.06 \\
Rye & $\mathrm{X}$ & $23(100)$ & $77(100)$ & $\mathrm{NC}$ \\
Vinegar & $\mathrm{X}$ & $21(91.3)$ & $52(67.5)$ & $5.08^{*}$ \\
Buckwheat & $\checkmark$ & $16(69.6)$ & $75(97.4)$ & $16.75^{*}$ \\
Couscous & $\mathrm{X}$ & $21(91.3)$ & $74(96.1)$ & 0.86 \\
Cocoa & $\checkmark$ & $19(82.6)$ & $75(97.4)$ & $6.87^{*}$ \\
Soy Sauce & $\mathrm{X}$ & $19(82.6)$ & $65(84.4)$ & 0.04 \\
Tomatoes & $\checkmark$ & $21(91.3)$ & $77(100)$ & 6.83 \\
Quinoa & $\checkmark$ & $22(100)$ & $77(100)$ & 3.38 \\
Eggs & $\checkmark$ & $20(87.0)$ & $77(100)$ & $10.35^{*}$ \\
\hline
\end{tabular}

524 Note: ${ }^{a}$ indicates the correct answers; NC - not computed as both males and females scored $100 \%$

525 (correct answers) for the particular food items; * denotes significant difference, $p<0.05$

528 Table 3 Percentage of grain consumption on a weekly basis $(n=100)$

\begin{tabular}{llllllll}
\hline Grains & \multicolumn{2}{l}{ Once/Week } & \multicolumn{2}{l}{ 3 Times/Week } & \multicolumn{2}{l}{$\chi^{\mathbf{2}}$} \\
\cline { 2 - 6 } & $\begin{array}{l}\text { Males } \\
(\%)\end{array}$ & $\begin{array}{l}\text { Females } \\
(\%)\end{array}$ & $\begin{array}{l}\text { Males } \\
(\%)\end{array}$ & $\begin{array}{l}\text { Females } \\
(\%)\end{array}$ & $\begin{array}{l}\text { Males } \\
(\%)\end{array}$ & $\begin{array}{l}\text { Females } \\
(\%)\end{array}$ & \\
\hline Buckwheat & 0 & 22.1 & 4.3 & 0 & 95.7 & 77.9 & $9.11^{*}$ \\
Amaranth & 17.4 & 11.7 & 0 & 0 & 82.6 & 88.3 & 0.51 \\
Quinoa & 65.2 & 49.4 & 8.7 & 16.9 & 26.1 & 33.8 & 1.96 \\
Rice & 60.9 & 53.2 & 39.1 & 45.5 & 0 & 1.3 & 0.65 \\
Corn & 65.2 & 54.5 & 17.4 & 31.2 & 17.4 & 14.3 & 1.67 \\
Sorghum & 0 & 11.7 & 4.3 & 2.6 & 95.7 & 85.7 & 3.07 \\
Fonio & 0 & 11.7 & 0 & 0 & 100 & 88.3 & 2.95 \\
Teff & 30.4 & 45.5 & 8.7 & 2.6 & 60.9 & 51.9 & 2.86 \\
Millet & 4.3 & 24.7 & 4.3 & 3.9 & 91.3 & 71.4 & 4.59 \\
Jobs Tears & 0 & 0 & 0 & 1.3 & 100 & 98.7 & 0.30 \\
\hline
\end{tabular}

*significant difference at $\mathrm{p}<0.05$

Table 4 Awareness of utilisation of AG in different food items $(n=100)$

\begin{tabular}{llllllllll}
\hline Grains & \multicolumn{3}{l}{ Amaranth } & \multicolumn{3}{c}{ Quinoa } & \multicolumn{4}{c}{ Buckwheat } \\
& $\begin{array}{l}\text { Males } \\
(\%)\end{array}$ & $\begin{array}{l}\text { Females } \\
(\%)\end{array}$ & $\chi^{2}$ & $\begin{array}{l}\text { Males } \\
(\%)\end{array}$ & $\begin{array}{l}\text { Females } \\
(\%)\end{array}$ & $\chi^{2}$ & $\begin{array}{l}\text { Males } \\
(\%)\end{array}$ & $\begin{array}{l}\text { Females } \\
(\%)\end{array}$ & $\chi^{2}$ \\
\hline $\begin{array}{l}\text { Chocolate } \\
\text { cake }\end{array}$ & 43.5 & 71.4 & $6.08^{*}$ & 47.8 & 61 & 1.27 & 43.5 & 80.5 & $12.05^{* *}$ \\
$\begin{array}{l}\text { Vegetable } \\
\text { soup }\end{array}$ & 47.8 & 62.3 & 1.54 & 78.3 & 67.5 & 0.97 & 43.5 & 70.1 & $5.46^{*}$ \\
$\begin{array}{l}\text { Tomato } \\
\text { pasta }\end{array}$ & 43.5 & 58.4 & 1.60 & 73.9 & 75.3 & 0.02 & 39.1 & 63.6 & 4.37 \\
Porridge & 60.9 & 68.8 & 0.51 & 82.6 & 59.7 & $4.07^{*}$ & 56.5 & 74 & 2.58
\end{tabular}




\begin{tabular}{llllllllll}
$\begin{array}{l}\text { Blueberry } \\
\text { muffins }\end{array}$ & 30.4 & 63.6 & $7.92 *$ & 78.3 & 66.2 & 1.1 & 21.7 & 75.3 & $21.82 * *$ \\
$\begin{array}{l}\text { Rice } \\
\text { pudding }\end{array}$ & 73.9 & 72.7 & 0.01 & 91.3 & 76.6 & 2.39 & 56.5 & 66.2 & 0.73 \\
\hline
\end{tabular}

*significant difference at $\mathrm{p}<0.05 ; * * \mathrm{p}<0.001$

534

535

Table 5 Time of diagnosis and awareness of utilisation of AG in food items $(n=100)$

\begin{tabular}{llll}
\hline Food Items & $\begin{array}{l}\text { Amaranth } \\
\chi^{2}(\mathbf{d f})\end{array}$ & $\begin{array}{l}\text { Quinoa } \\
\chi^{2}(\mathbf{d f})\end{array}$ & $\begin{array}{l}\text { Buckwheat } \\
\chi^{2}(\mathbf{d f})\end{array}$ \\
\hline Chocolate cake & $\chi^{2}(3)=7.809$ & $\chi^{2}(3)=18.806^{* *}$ & $\chi^{2}(3)=4.430$ \\
Vegetable soup & $\chi^{2}(3)=14.729^{*}$ & $\chi^{2}(3)=12.988^{*}$ & $\chi^{2}(3)=20.466^{* *}$ \\
Tomato pasta & $\chi^{2}(3)=18.331^{* *}$ & $\chi^{2}(3)=6.173$ & $\chi^{2}(3)=12.275^{*}$ \\
Porridge & $\chi^{2}(3)=16.874^{*}$ & $\chi^{2}(3)=32.764^{*}$ & $\chi^{2}(3)=21.030^{*}$ \\
Blueberry & $\chi^{2}(3)=16.961^{*}$ & $\chi^{2}(3)=12.142^{*}$ & $\chi^{2}(3)=9.229 *$ \\
muffins & & & \\
Rice pudding & $\chi^{2}(3)=18.655^{* *}$ & $\chi^{2}(3)=14.437^{*}$ & $\chi^{2}(3)=20.363^{* *}$ \\
\hline
\end{tabular}

